\title{
Characteristics of nanocrystalline thin films of cadmium sulphide deposited at the water-oil interface
}

Baxter, Sean; Albrasi, Enteisar; Kelly, Aoife J.; Johal, Sukhraaj ; Prabhakar, John Thomas

\section{Journal of Colloid and Interface Science}

DOI:

10.1016/j.jcis.2017.02.044

Published: 15/06/2017

Peer reviewed version

Cyswllt i'r cyhoeddiad / Link to publication

Dyfyniad o'r fersiwn a gyhoeddwyd / Citation for published version (APA):

Baxter, S., Albrasi, E., Kelly, A. J., Johal, S., \& Prabhakar, J. T. (2017). Characteristics of nanocrystalline thin films of cadmium sulphide deposited at the water-oil interface. Journal of Colloid and Interface Science, 496, 474-478. https://doi.org/10.1016/j.jcis.2017.02.044

\footnotetext{
Hawliau Cyffredinol / General rights

Copyright and moral rights for the publications made accessible in the public portal are retained by the authors and/or other copyright owners and it is a condition of accessing publications that users recognise and abide by the legal requirements associated with these rights.

- Users may download and print one copy of any publication from the public portal for the purpose of private study or research.

- You may not further distribute the material or use it for any profit-making activity or commercial gain

- You may freely distribute the URL identifying the publication in the public portal ?
}

Take down policy

If you believe that this document breaches copyright please contact us providing details, and we will remove access to the work immediately and investigate your claim. 


\title{
Characteristics of Nanocrystalline Thin Films of Cadmium Sulphide Deposited at the Water-Oil Interface
}

\author{
Enteisar Albrasi ${ }^{1,2}$, Aoife J. Kelly ${ }^{1}$, Paul O’Brien ${ }^{1}$, Sean N. Baxter ${ }^{3}$, P. John Thomas ${ }^{3, *}$
}

\begin{abstract}
Thin films of nanocrystalline CdS were obtained at the water-toluene interface by reacting cadmium diethyldithiocarbamate in toluene with aq. $\mathrm{Na}_{2} \mathrm{~S}$. Three parameters unique to the topical deposition scheme: the effect of column heights, stirring and the action of molecular surfactants are systematically investigated. The obtained nanocrystalline aggregates are characterized by scanning- and transmission electron microscopy, X-ray diffraction and profilometric measurements. Conditions for obtaining smooth device quality thin films have been identified during these experiments.
\end{abstract}

Keywords: CdS, nanocrystals, interfacial deposition, thin films, nanoparticles.

\section{Introduction}

The area surrounding the interface between water and oil is emerging as a exciting medium for the growth and deposition of nanocrystalline thin films[1-5]. Starting with molecular precursors, nanostructured forms of topical materials such as: $\mathrm{Au}, \mathrm{Ag}, \mathrm{CdS}, \mathrm{PbS}, \mathrm{ZnS}, \mathrm{Fe}_{2} \mathrm{O}_{3}$ and $\mathrm{CeO}_{2}$ as well as graphene composites [6; 7] have been obtained using this technique. Detailed studies have been carried out in an attempt to uncover the growth mechanism, particularly in the case of Au using X-ray scattering, photoelectron spectroscopy and electron microscopy.[3; $5 ; 8 ; 9]$ The interfacial deposition scheme is low cost, soft, scalable and is potentially capable of depositing films over large areas. In a typical reaction, a metal precursor dissolved in toluene is layered atop an aqueous column containing a precipitation agent such as $\mathrm{Na}_{2} \mathrm{~S}$. If suitable precursors are chosen, the reaction proceeds at the region of contact between the two liquids and yields a film adhered to the water-oil interface. The deposit can then be transferred to a substrate of choice.

Despite the apparent simplicity of the scheme, processes underpinning interfacial precipitation are complex. Current understanding of surface potentials, diffusion and heat transport mechanisms across water-oil interface are insufficient to advance the area. Even the very nature of the interface between liquids such as water and toluene is subject to much debate.[1] Modelling or predicting the course or the outcome of an interfacial reaction is therefore fraught with difficulty. At present progress in this area is largely driven by experiments. It has be shown empirically that properties of deposits can be controlled by adapting different reaction conditions such as time, temperature and reagent concentrations.[1; 3] However, parameters

\footnotetext{
*For correspondence: john.thomas@bangor.ac.uk

${ }^{1}$ School Chemistry and School of Materials, Oxford Road, The University of Manchester, Manchester M139PL, UK.

${ }^{2}$ At present: Department of Chemistry, University of Benghazi, Faculty of Education, 3188, Benghazi, Libya.

${ }^{3}$ School of Chemistry, Bangor University, Bangor, LL57 2UW, UK.
}

unique to the technique such as the role of column heights and effect of molecular surfactants are virtually unexplored. The former can significantly alter interfacial pressure leading to deposits with new and interesting forms[1]. We considered it important to systematically explore the influence of such factors in dictating the macroscopic structure and properties of the interfacial deposits. We have chosen to study nanocrystalline thin films of CdS, a II-VI semiconductor with a band gap of $2.42 \mathrm{eV}$, an established photo-conductor with several current and many potential uses.[10-13]

\section{Methods and Materials}

The cadmium diethyldithiocarbamate precursor for the deposition of interfacial films was prepared following previous reports. Briefly, $15 \mathrm{mmol}$ diethylamine and $15 \mathrm{mmol}$ of carbon disulfide were added to a stirred $40 \mathrm{ml}$ methanol containing 20 mmol sodium hydroxide. The addition was marked by the solution turning pale yellow. The mixture was then cooled to $4^{\circ} \mathrm{C}$ using an ice bath and a $40 \mathrm{ml}$ methanol solution containing 7 mmol cadmium chloride was added dropwise resulting in formation of a pale yellow precipitate. The solid was isolated and purified by re-crystallizing from toluene. Elemental analysis: found (\%) (calculated): C 29.56 (30.00); H 4.57 (4.80); N 6.82 (6.80); S 30.67 (31.00); Cd 27.32 (27.40).

Deposition of CdS thin film at the water-toluene interface: CdS thin film was prepared by layering $30 \mathrm{ml}$ of toluene containing $0.12 \mathrm{mmol}$ cadmium diethyldithiocarbamate over a $30 \mathrm{ml}$ aqueous column containing $0.25 \mathrm{mmol} \mathrm{Na}_{2} \mathrm{~S}$ in a beaker. The reaction vessel was introduced into an oven preheated to the desired temperature for different times. Following heating, the entire area of contact between the two liquids tuned to yellow signalling the formation of $\mathrm{CdS}$ thin film. The liquid phases stayed colourless. The thin film at the interface was transferred to different supports by dipping the substrates at an incline across the interface and moving them gradually upward. 

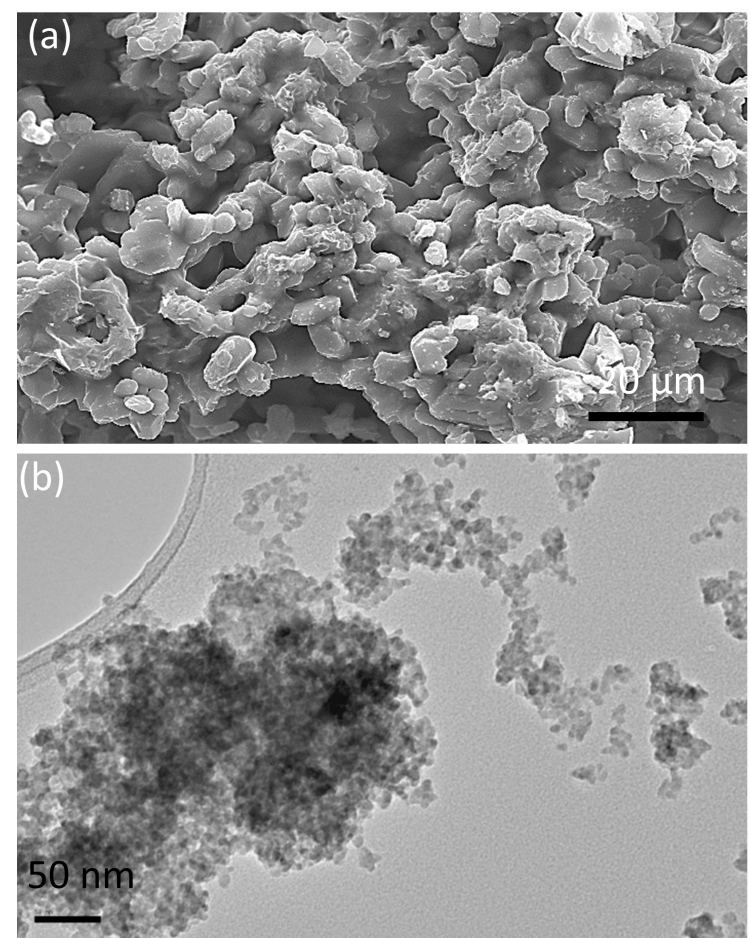

Figure 1: Electron Microscopic images of CdS nanocrystalline films. The films were obtained by reacting $30 \mathrm{ml}$ of $33.3 \mathrm{mM}$ aqueous $\mathrm{Na}_{2} \mathrm{~S}$ and $30 \mathrm{ml}$ of $0.5 \mathrm{M}$ toluene solution of $\mathrm{Cd}\left(\mathrm{S}_{2} \mathrm{CNEt}_{2}\right)_{2}$ at $40{ }^{\circ} \mathrm{C}$ after 2 hours.

Characterization:X-ray diffraction was carried out with a Philips Xpert diffractometer utilizing monochromatic $\mathrm{CuK} \alpha$ radiation. Samples for diffraction consisted of precipitates deposited on glass substrates. Scanning electron microscopy (SEM) was carried out with Philips Excel microscope equipped with a $30 \mathrm{kV}$ field emission gun or Delong Instruments LVEM5, low-voltage electron microscope.

\section{Results and Discussion}

Standard conditions for CdS deposition was a reaction carried out at $40^{\circ} \mathrm{C}$ for two hours. Following this scheme, smooth and continuous thin film CdS deposits strongly adhered to the interface are obtained and were subsequently transferred to glass substrates. The following reactions take place in the vessel:

$$
\begin{gathered}
\mathrm{Cd}\left(\mathrm{S}_{2} \mathrm{CNEt}_{2}\right)_{(\text {oil) }}+\mathrm{Na}_{2} \mathrm{~S}_{\text {(aq.) }} \longrightarrow \\
\mathrm{CdS}_{\text {(interface) }}+\mathrm{Na}\left(\mathrm{S}_{2} \mathrm{CNEt}_{2}\right)_{(\text {aq. })}
\end{gathered}
$$

Scanning electron microscopy revealed growths that formed a were crack-free nebulous network dominated by microscopic platelets with rounded edges. High resolution imaging revealed coarse grained surfaces on the deposits hinting at a possible nanostructure (see figure 1a). Transmission electron microscopy carried out on interfacial growths treated with ultrasound to separate flocculates revealed that the films consists of nearly spherical crystallites with average diameter of $7.0 \mathrm{~nm}$ (figure 1b). $\mathrm{X}$-ray diffraction pattern consists of broader than usual peaks characteristic of fine particulates of hexagonal CdS (see figure

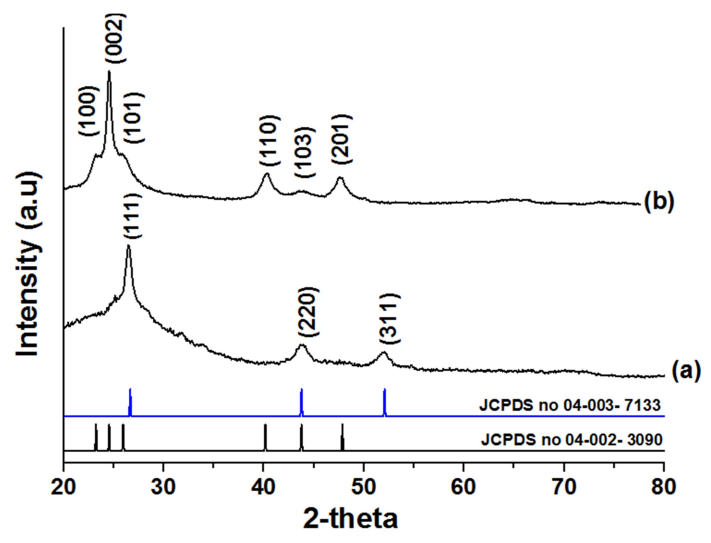

Figure 2: X-ray diffraction pattern of CdS thin films grown (a) with octylamine and (b) without octylamine. The standard reference patterns for cubic and hexagonal forms are indicated below.

2a). Profilometric measurements on flat glass substrates yielded average thickness of $90 \mathrm{~nm}$. The measured grain size and thickness are inline with a previous report of interfacial CdS obtained under similar conditions[14]. A effect on different variables on the standard scheme are presented below.

Effect of surfactants: Three surfactants with proven ability to bind to CdS: octylamine, tri-n-octylphosphine oxide(TOPO) and tetra-octylammmonium bromide(TOAB) were introduced in different quantities at the start of the reaction to evaluate their effects on the growth and deposition of thin films. The affinity of octylamine and TOPO to CdS is well established and routes to alkylamine or TOPO/TOP capped CdS nanocrystals abound.[15; 16] TOAB is less well-known, but has been shown to quench luminescence by binding to the surface of $\mathrm{CdS}$ quantum dots.[17] We find that the introduction of the surfactants noticeably slows down interfacial deposition. In order to achieve films thickness of $90 \mathrm{~nm}$, the deposition time had to be doubled to four hours. X-ray diffraction patterns (see figure 2) are consistent with cubic CdS. Here, the deposits appeared to consist of cubic rather than hexagonal nanocrystallites of CdS. Such a phase change is significant as routes to cubic thin films of CdS are rare.[18-20] However, the broader than usual peak widths caused in part by the fine grained nature of the deposits makes unambiguous assignment difficult.

In addition to influencing the crystal structure, the surfactants have a profound effect on the microstruture and morphology of the interfacial deposits. We find broadly similar effects in the case of each of the surfactants, with concentration relative to metal precursor being the key parameter. At low concentration ratios (1:0.01, metal:surfactant), smooth films with vein like deposits are seen in the scanning electron micrographs (see figure 3 ). This is in contrast to the nebulous structures in figure 1a. Intermediate quantities in the range of 1:0.05-1:0.1, yield interfacial deposits with well defined hexagonal cells with longest dimension around 1.3-1.8 $\mu \mathrm{m}$ with around $100 \mathrm{~nm}$ separation between the cells. Such mesostructured assemblies are novel are hitherto unreported following the interfacial deposition scheme. The assembly process is fragile and is critically 


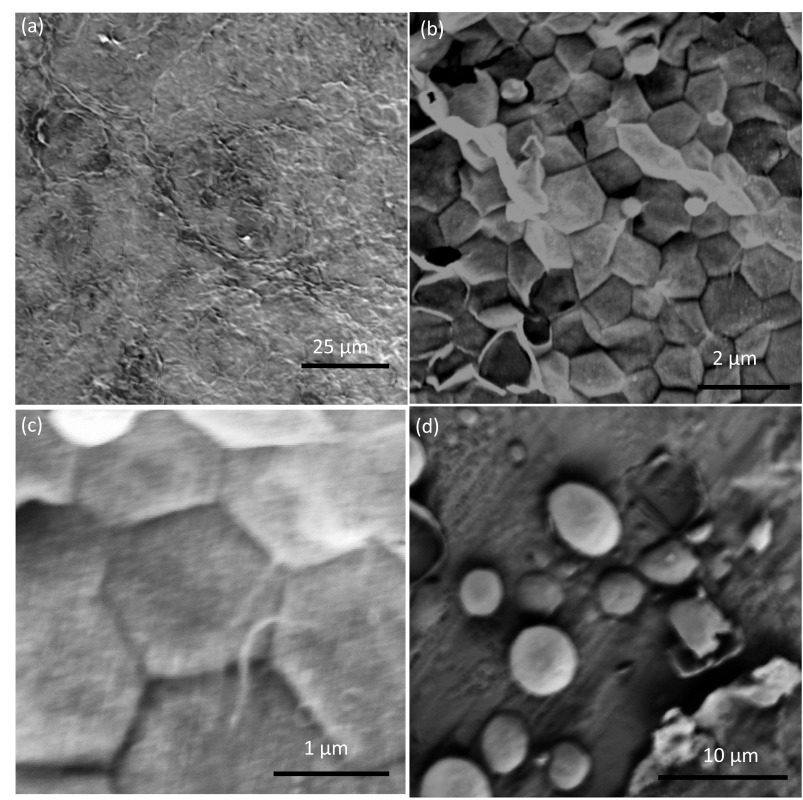

Figure 3: Scanning electron micrographs of CdS films grown in the presence of different quantities of octylamine. All of the deposits were obtained with $30 \mathrm{ml}$


Figure 4: Scanning electron micrographs of CdS deposits obtained with toluene column heights of: (a) $4 \mathrm{~cm}$; (b) $6 \mathrm{~cm}$ and (c) $8 \mathrm{~cm}$.
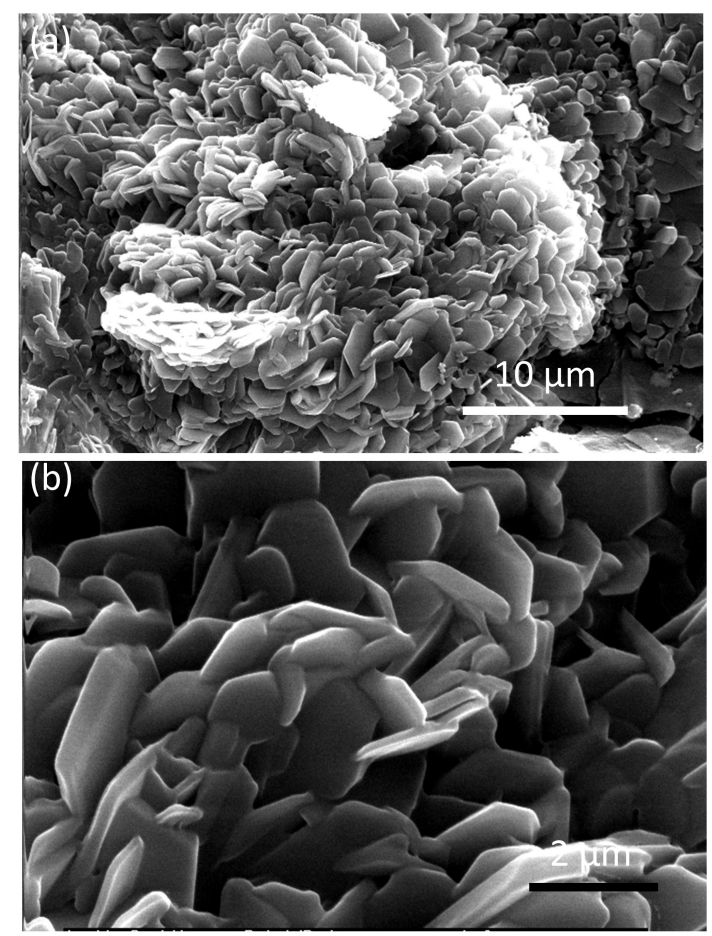

Figure 5: Scanning electron micrographs of CdS deposits obtained while the two liquids are stirred with high speed orbital mixer.

dependent on the metal ion:surfactant ratio. Higher concentrations of surfactants lead to collapse of assembly leading to precipitates that consist of spheriodal overlayers on a smooth deposit(figure $3 \mathrm{~d}$ ). The ubiquity of these structures (we obtained these using three different surfactants) suggests that the assembly process is robust, generic and is perhaps independent of specific particle-surfactant interaction effects. We are as yet unable to ascertain the underlying cause of this process. We speculate that these large mesoscaler patterns are a result of pattern forming convection currents at the interface of two-fluids.[21-23]

Effect of Height: A series of experiments with different column heights of toluene were carried out in custom made tall form beakers. In these set of experiments, different volumes of the same stock solution of toluene was used and the concentration of the aq. layer increased to compensate for the increase quantity of the metal precursor. The column height was increased from $2 \mathrm{~cm}$ to $8 \mathrm{~cm}$. This change in height corresponds to an increase in pressure on an individual $7.0 \mathrm{~nm}$ grain of $\mathrm{CdS}$ from $8.57 \times 10^{-11} \mathrm{mN} \mathrm{nm}^{-2}$ to $3.43 \times 10^{-10} \mathrm{mN} \mathrm{nm}^{-2}$. For comparison, the pressure change herein is an order of magnitude higher than those accessible in a typical Langmuir-Blodgett deposition scheme.[1] The greatest height yielded very smooth films (compare figure $4 \mathrm{c}$ and $1 \mathrm{a}$ ). There were no tangible change in other characteristics of the film including grain size, thickness and crystal structure. It is possible to make reliable contacts to carry out charge transport measurements on films of such quality. The sheet resistance of the thin film grown using a column height of $8 \mathrm{~cm}$ was $2 \times 10^{5} \Omega \mathrm{cm}^{-2}$ and two orders of magnitude lower than those deposited at the shortest 
level of $2 \mathrm{~cm}$. The fall is possibly due to better contact being established with the smoother surface of the former. The resistance values of the smooth layers herein are comparable to those of high quality films obtained using high temperature schemes such as vapour deposition.[24]

Effect of Stirring: Unlike in a traditional bath deposition, stirring has a different role in the interfacial scheme. Agitation of the contents of the beaker using a high speed orbital mixer during the deposition process is expected to lead to a greater area of contact between the two liquids as the original liquid inteface is broken into smaller fragments. Heat flow, particularly across the water-oil interface is likely to be affected to some extent.[25; 26] However, it appears clear from previous literature concerned with transport across fluid interfaces that stirring does not actually promote greater mixing of ions.[27] We find that introduction of stirring leads to significant changes to the microstructure of the films. The deposits produced by stirring contain clear hexagonal platelets that form a macroscopic aggregate (see figure 5). Each of these platelets are about a micron wide and around $90 \mathrm{~nm}$ thick. We believe that the individual platelets adorn the droplets formed during the stirring process and come together to form loose interfacial aggregates at the end of mixing prior to transfer to substrate.

\section{Conclusion}

In summary, change of height, introduction of stirring and the use of surfactants produce tangible changes to the microand mesostructure of the films and extend as far as to influence the crystal structure of the obtained nanocrystalline CdS film. Smooth, device quality films of CdS can be produced by increasing the height of the toluene column to $8 \mathrm{~cm}$. Apparently cubic CdS can be obtained by introducing surfactants during the deposition. For the first time, interfacial deposits were found to adopt mesoscalar structures when under the influence of stirring or the introduction of surfactants during growth. The cause of such an assembly is currently uncertain and could be a topic of future studies. The dithiocarbamate family of metal precursors have proven useful in the interfacial growth of nanocrystalline forms of $\mathrm{ZnS}[14], \mathrm{PbS}[28], \mathrm{Bi}_{2} \mathrm{~S}_{3}$ [29] and $\mathrm{Cd}(\mathrm{OH})_{2}$ [30]. We envisage that the conclusions of this study can be applied to the broad range of materials following the route indicated.

\section{References}

[1] P. J. Thomas, E. Mbufu, P. O'Brien, Thin films of metals, metal chalcogenides and oxides deposited at the water-oil interface using molecular precursors, Chem. Commun. 49 (2013) 118-127.

[2] R. A. W. Dryfe, Modifying the liquid/liquid interface: pores, particles and deposition, Phys. Chem. Chem. Phys. 8 (2006) 1869.

[3] C. N. R. Rao, K. P. Kalyanikutty, The liquid-liquid interface as a medium to generate nanocrystalline films of inorganic materials, Acc. Chem. Res. 41 (4) (2008) 489-499.

[4] S. G. Booth, R. A. W. Dryfe, Assembly of nanoscale objects at the liquid/liquid interface, J. Phys. Chem. C 119 (2015) 23295.

[5] R. A. W. Dryfe, A. Uehara, S. G. Booth, Metal deposition at the liquidliquid interface, Chem. Rec. 14 (2014) 1013.

[6] K. Bramhaiah, N. S. John, Hybrid films of reduced graphene oxide with noble metal nanoparticles generated at a liquid/liquid interface for applications in catalysis, RSC Adv. 3 (2013) 7765-7773.
[7] K. Bramhaiah, V. N. Singh, N. S. John, Hybrid materials of ZnO nanostructures with reduced graphene oxide and gold nanoparticles: enhanced photodegradation rates in relation to their composition and morphology, Phys. Chem. Chem. Phys. 18 (2016) 1478-1486.

[8] S. G. Booth, A. Uehara, S. Y. Chang, J. F. W. Mosselmans, S. L. M. Schroeder, R. A. W. Dryfe, Gold deposition at a free-standing liquid/liquid interface: Evidence for the formation of $\mathrm{Au}(\mathrm{I})$ by microfocus $\mathrm{X}$-ray spectroscopy (mu xrf and mu xafs) and cyclic voltammetry, J. Phys. Chem. C 119 (2015) 16785.

[9] A. Uehara, T. Hashimoto, R. A. W. Dryfe, Au electrodeposition at the liquid-liquid interface: mechanistic aspects, Electrochem. Acta. 118 (2014) 26.

[10] P. R. Herczfeld, Low frequency oscillations in CdS photo-conductors induced by optical quenching, Physica 39 (1968) 439.

[11] J. He, W. Ji, G. H. Ma, S. H. Tang, E. S. W. Kong, S. Y. Chow, X. H. Zhang, Z. L. Hua, J. L. Shi, Ultrafast and large third-order nonlinear optical properties of CdS nanocrystals in polymeric film, J. Phys. Chem. B (2005) 4373.

[12] K.L.Chorpra, P.D.Paulson, V.Dutta, Thin-film solar cells: an overview, Prog. Photovoltaics: Res. Appl. 12 (2004) 69.

[13] H. J. Kim, C.-W. Kim, D. Y. Jung, C. Jeong, Effect of reaction temperature of CdS buffer layers by chemical bath deposition method, J. Nanosci. Nanotechnol. 16 (2016) 5114.

[14] D. Fan, P. J. Thomas, P. O'Brien, Deposition of CdS and ZnS thin films at the water/toluene interface, J. Mater. Chem. 17 (2007) 1381.

[15] C. N. R. Rao, P. J. Thomas, G. U. Kulkarni, Nanocrystals: Synthesis, Properties and Applications, Springer, 2007.

[16] V. Rotello (Ed.), Nanoparticles: Building Blocks for Nanotechnology, Springer, 2012.

[17] T. Hiratani, K. Konishi, Surface-cap-mediated host-guest chemistry of semiconductor CdS: Intercalative cation accumulation around a phenylcapped CdS cluster and its notable effects on the cluster photoluminescence, Angew. Chem. Intl. Ed. 116 (44) (2004) 6069-6072.

[18] I.-H. Choi, P. Y. Yu, Structural and optical properties of cubic-CdS and hexagonal-CdS thin films grown by MOCVD on GaAs substrates using a single-source precursor $\mathrm{C}_{14} \mathrm{H}_{30} \mathrm{CdN}_{2} \mathrm{~S}_{4}$, Phys. Stat. Sol. (b) 242 (2005) 1610.

[19] R. Lozada-Morales, O. Zelaya-Angel, G. Torres-Delgado, Photoluminescence in cubic and hexagonal CdS films, App. Surf. Sci. 175-176 (2001) 562 - 566, 10th International Conference on Solid Films and Surfaces.

[20] O. Zelaya-Angel, L. Hernandez, O. de Melo, J. Alvarado-Gil, R. LozadaMorales, C. Falcony, H. Vargas, R. Ramirez-Bon, Band-gap shift in CdS: phase transition from cubic to hexagonal on thermal annealing, Vacuum 46 (8) (1995) $1083-1085$.

[21] M. C. Cross, P. C. Hohenberg, Pattern formation outside of equilibrium, Rev. Mod. Phys. 65 (1993) 851-1112.

[22] A. Golovin, A. Nepomnyashchy, L. Pismen, Pattern formation in largescale marangoni convection with deformable interface, Physica D: Nonlinear Phenomena 81 (1995) 117 - 147.

[23] L. Shtilman, G. Sivashinsky, Hexagonal structure of large-scale marangoni convection, Physica D: Nonlinear Phenomena 52 (1991) 477 -488 .

[24] C. Kumar, N. Hoa, S.-G. Yoon, E.-T. Kim, J.-H. Lee, G.-H. Kim, Highly photoconductive CdS thin films synthesized by using chemical bath deposition, J. Kor. Phys. Soc. 55 (2009) 284.

[25] J. T. Davies, E. Rideal, Interfacial Phenomena (2nd ed.), Academic Press (New York), 1963.

[26] A. G. Volkov, D. W. Deamer, D. L. Tanelian, Liquid interfaces in chemistry and biology, Wiley, (Weinheim), 1998.

[27] I. Benjamin, Static and dynamic electronic spectroscopy at liquid interfaces, Chem. Rev. 106 (2006) 1212.

[28] D. Fan, P. J. Thomas, P. O’Brien, Pyramidal lead sulfide crystallites with high energy \{113\} facets, J. Am. Chem. Soc 130 (2008) 10892.

[29] D. Fan, P. J. Thomas, P. O'Brien, Synthesis and assembly of $\mathrm{Bi}_{2} \mathrm{~S}_{3}$ nanoparticles at the water-toluene interface, Chem. Phys. Lett. 465 (2008) 110.

[30] S. N. Mlondo, E. M. Andrews, P. J. Thomas, P. O'Brien, Deposition of hierarchical $\mathrm{Cd}(\mathrm{OH})_{2}$ anisotropic nanostructures at the water-toluene interface and their use as sacrificial templates for cdo or cds nanostructures, Chem. Commun (2008) 2768. 